Decentralized Nonmonetary Trade

Author(s): Ross M. Starr

Source: Econometrica, Vol. 44, No. 5 (Sep., 1976), pp. 1087-1089

Published by: The Econometric Society

Stable URL: http://www.jstor.org/stable/1911547

Accessed: 19/07/2011 17:51

Your use of the JSTOR archive indicates your acceptance of JSTOR's Terms and Conditions of Use, available at http://www.jstor.org/page/info/about/policies/terms.jsp. JSTOR's Terms and Conditions of Use provides, in part, that unless you have obtained prior permission, you may not download an entire issue of a journal or multiple copies of articles, and you may use content in the JSTOR archive only for your personal, non-commercial use.

Please contact the publisher regarding any further use of this work. Publisher contact information may be obtained at http://www.jstor.org/action/showPublisher?publisherCode=econosoc.

Each copy of any part of a JSTOR transmission must contain the same copyright notice that appears on the screen or printed page of such transmission.

JSTOR is a not-for-profit service that helps scholars, researchers, and students discover, use, and build upon a wide range of content in a trusted digital archive. We use information technology and tools to increase productivity and facilitate new forms of scholarship. For more information about JSTOR, please contact support@jstor.org. 


\title{
DECENTRALIZED NONMONETARY TRADE
}

\author{
BY Ross M. StarR ${ }^{1}$
}

\begin{abstract}
"[Money] is a machine for doing quickly and commodiously, what would be done, though less quickly and commodiously, without it."
\end{abstract}

J. S. Mill, Principles of Political Economy (III : VII 3)

IT IS SHOWN in [2] that the use of money in trade allows the achievement of an equilibrium allocation of commodities in fixed trading time; the allocation could otherwise be achieved without the use of money in a fashion requiring more elaborate organization of the trading process. This confirms Mill's contention on the "commodious" nature of monetary trade. This note investigates a nonmonetary trading procedure with organization no more elaborate than monetary trade but requiring more trading time for achievement of an equilibrium allocation. Once again Mill's contention is verified. The nonmonetary process is equally commodious (simple in its organization) but a good deal slower.

The theorem below, in conjunction with Theorems 2 and 4 of [2], develops the trade-off between time required to achieve equilibrium allocation and the use of money. The restrictions on bilateral trade implied by constraints of nonnegativity, quid pro quo, and informational decentralization are investigated in [1 and 2]. It is argued [2, Theorem 4] that a medium of exchange universally held in quantity sufficient to finance intended net purchases allows trade to an equilibrium allocation to be achieved in a single sequence of meetings (one for each pair) among the traders of an economy. Consider trade similarly restricted in the absence of a universally held medium of exchange. Theorem 2 in [2] says that, in this case, it will not generally be possible to achieve the equilibrium allocation in a single round of decentralized trade. The analysis of nonmonetary trade below shows that if the time available for trade is extended, a decentralized process converges geometrically to the equilibrium allocation.

The trading process represents a barter procedure without a restriction of double coincidence of wants; it may be viewed as a "monetary" procedure where all goods act as "money". The analysis of [2] suggested that the use of money economizes on information (with respect to individual traders' excess supplies and demands) and coordination. The theorem below says alternatively that the use of money economizes on trading time. Barter mechanisms can succeed as quickly as monetary trade if coordination and sufficient market information are freely available [2, Theorem 2]. In their absence, successful barter may require much longer.

All notation and conventions are taken from [2].

\section{DECENTRALIZED NONMONETARY TRADE, RULE $\gamma$}

An anarchic, intuitive, and informationally decentralized approach is for traders to trade in all goods such that one agent has an excess supply and the other an excess demand, until the smaller of the two is exhausted. Quid pro quo is then maintained by payment from the debtor to the creditor in goods of which the debtor has an excess supply. This is rule $\gamma$ of [2] and it works essentially as the monetary trade rule (rule $\mu$ of [2]) with all goods indiscriminately acting as media of exchange. If rule $\gamma$ is followed for several rounds the value of unsatisfied excess demand remaining at the end of round $v$ converges to 0 as $(1 / 2)^{v}$. I have not been able

${ }^{1} \mathrm{I}$ am indebted to Joseph Ostroy for collaboration in an earlier essay. Errors are my own. The hospitality of the London School of Economics and the Institute for Mathematical Studies in the Social Sciences, Stanford University was very helpful. The support of the Cowles Foundation for Research in Economics at Yale University is gratefully acknowledged. The research described in this paper was undertaken by grants from the National Science Foundation and from the Ford Foundation. 
to show that full execution will be achieved in finite time, nor have I been able to discover an example where trading rule $\gamma$ continues indefinitely without achieving full execution.

Recall that $v_{i n}^{t}$ is $i$ 's unsatisfied excess demand or supply of commodity $n$.

Trading RULE $\gamma$ : For $\pi^{t}(i)=j$, let $a_{i}^{t}=x_{i}^{t}+y_{i}^{t}$ and $a_{j}^{t}=x_{j}^{t}+y_{j}^{t}$ where

$$
x_{i n}^{t}=-x_{j n}^{t}=\left\{\begin{aligned}
0 & \text { if } v_{i n}^{t} v_{j n}^{t} \geqslant 0, \\
\min \left(\left|v_{i n}^{t}\right|,\left|v_{j n}^{t}\right|\right) & \text { if } v_{i n}^{t}>0 \text { and } v_{j n}^{t}<0, \\
-\min \left(\left|v_{i n}^{t}\right|,\left|v_{j n}^{t}\right|\right) & \text { if } v_{i n}^{t}<0 \text { and } v_{j n}^{t}>0,
\end{aligned}\right.
$$

and $y_{i}^{t}=-y_{j}^{t}$ is constructed according to

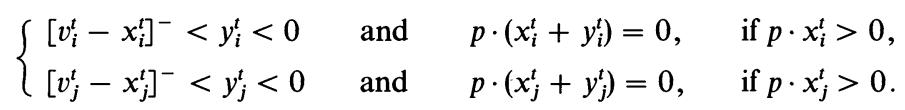

Part (1) says that when $i$ and $j$ meet to trade they scan their respective excess supplies and demands to see if $i$ has an excess supply in a good of which $j$ has an excess demand or if $j$ has an excess supply of a good for which $i$ has an excess demand. If so, the goods go from the supplier to the demander in quantity sufficient to exhaust the excess supply or fulfill the excess demand, whichever is smaller. This trade will usually leave one of the traders a net debtor to the other: Part (2) specifies that the debtor settle accounts by sending to the creditor goods of sufficient value from his excess supplies.

Rule $\gamma$ fulfills all the conditions of [2]. It is decentralized [2, D.1] requiring of $i$ and $j$ that they base their trading decision only on their own current excess demands and supplies. Rule $\gamma$ is even less informationally demanding than the monetary trade rule $\mu$ of [2] since $\gamma$ does not require that one distinguish a specific universally-agreed-upon commodity as "money". Nonnegativity [2, A.1] follows since traders deliver only their excess supplies. Pairwiseness [2, A.2] is definitional. Quid pro quo [2, A.3], that traders pay for what they get, comes directly from (2) in the specification of $\gamma$.

Rule $\gamma$ implies a lower bound on the volume of trade. In the course of one round all outstanding excess supplies must be traded at least once (see Lemma 2, below). But no more than half (in value terms) of an exchange can be for maintenance of quid pro quo. The remainder according to rule $\gamma$ must be for fulfillment of excess demands. Thus, in the course of each round, at least half of the excess demands outstanding at the start of the round are fulfilled (Lemma 3). Geometric convergence to the equilibrium allocation then follows by iteration.

LEMMA 1: Let trade proceed by rule $\gamma$. Then $k \geqslant 0, v_{i n}^{t} \leqslant 0$ imply $v_{i n}^{t+k} \leqslant 0$.

Lemma 1 notes that rule $\gamma$ will never ailow an excess supply to be changed to an excess demand.

LEMma $2:^{2}$ Let trade proceed by rule $\gamma$. Then for each $i, n,\left|\Sigma_{T=1}^{\tau}\left[a_{i n}^{t+T}\right]^{-}\right| \geqslant\left|\left[v_{i n}^{t}\right]^{-}\right|$.

Lemma 2 says that during one round, each trader must engage in transactions in each commodity at least as great as the excess supplies of the commodity he held at the start of the round. The argument for this is simple. For each such excess supply, either the holder will trade it when he meets a demander or he will have already spent it in paying for a desired acquisition. By Lemma 1, he will confront during one round demanders for all the excess supplies with which he started the round. Hence, the result is established.

\footnotetext{
${ }^{2}$ Recall the following notations from [2]. $\tau$ is the number of trading periods in one round. In $\tau$ periods each trader meets each other trader precisely once. $[x]^{-} \equiv \min [0, x] ;[x]^{+}=\max [0, x]$. If $x$ is a vector, $[x]^{+}=\left(\left[x_{1}\right]^{+},\left[x_{2}\right]^{+}, \ldots,\left[x_{N}\right]^{+}\right)$.
} 
LeMma 3: Let trade proceed by rule $\gamma . \Sigma_{i} p \cdot\left[v_{i}^{t+\tau}\right]^{+} \leqslant \frac{1}{2} \Sigma_{i} p \cdot\left[v_{i}^{t}\right]^{+}$.

Lemma 3 says that in one round of trade ( $\tau$ trading periods) the value at $p$ of unsatisfied demand remaining at the end of the round must be no more than half what it was at the start of the round. From Lemma 2 we know that the value of the total volume of trade in the round evaluated at $p$ must be at least as large as the value of excess demands at the beginning of the round. Trade is either to satisfy demands or fulfill quid pro quo. But, by the specification of $\gamma$, no more than half of the trade can be for quid pro quo because to each of the latter corresponds a demand fulfilling trade. Further, by Lemma 1, supplies are not converted to demands. Thus, in one round of trade the value of unsatisfied demands is reduced to, at most, half of its previous level. The theorem then follows merely by iteration of Lemma 3.

THEOREM: Let trade proceed by rule $\gamma$. For $v=1,2, \ldots, \Sigma_{i} p \cdot\left[v_{i}^{1+\nu \tau}\right]^{+} \leqslant\left(\frac{1}{2}\right)^{v} \Sigma_{i} p \cdot\left[z_{i}\right]^{+}$.

ProOF OF LeMMA 1: $v_{i n}^{t} \leqslant 0$ implies $v_{i n}^{t} \leqslant x_{i n}^{t} \leqslant 0$.

Case 1:

$$
\begin{aligned}
& 0 \geqslant y_{i n}^{t} \geqslant v_{i n}^{t}-x_{i n}^{t}, \\
& v_{i n}^{t+1}=v_{i n}^{t}-\left(x_{i n}^{t}+y_{i n}^{t}\right), \\
& 0 \geqslant v_{i n}^{t}-x_{i n}^{t}-y_{i n}^{t}=v_{i n}^{t+1} .
\end{aligned}
$$

Case 2:

$$
\begin{aligned}
& y_{i n} \geqslant 0, \\
& v_{i n}^{t}-x_{i n}^{t} \leqslant 0, \quad v_{i n}^{t+1}=v_{i n}^{t}-\left(x_{i n}^{t}+y_{i n}^{t}\right), \\
& v_{i n}^{t+1}=v_{i n}^{t}-x_{i n}^{t}-y_{i n}^{t} \leqslant 0 .
\end{aligned}
$$

Thus, $v_{i n}^{t+1} \leqslant 0$. By $k$-fold replication of the same argument $v_{i n}^{t+k} \leqslant 0$.

Q.E.D.

Proof of Lemma 2: If $v_{i n}^{t}=0$ the result follows trivially. Consider $i, n$ so that $v_{i n}^{t}<0$. Let $i$ and $j$ meet in $t+T_{j}$. For each commodity $n$, define $l(n) \subset I$ so that $j \in l(n)$ if and only if $v_{j n}^{t}>0$. Consider $\Sigma_{j \in I(n)} v_{j n}^{t+T_{j}}$.

Case 1: $\Sigma_{j \in l(n)} v_{j n}^{t+T_{j}}=0$. By Lemma 1, under rule $\gamma$ this can occur only if $\left|\Sigma_{T=1}^{\tau}\left[a_{i n}^{t+T}\right]^{-}\right| \geqslant$ $\left|v_{i n}^{t}\right|$ and we are done.

Case 2: $\Sigma_{j \in l(n)} v_{j n}^{t+T_{J}}>0$. For each $j \in l(n)$ either $v_{i n}^{t+T_{j}}=0$ and we are done, or $v_{i n}^{t+T_{J}}<0$ and $a_{i n}^{t+T_{j}}=-\min \left(\left|v_{j n}^{t+T_{j}}\right|,\left|v_{i n}^{t+T_{j}}\right|\right)$. Then either $a_{i n}^{t+T_{j}}=v_{i n}^{t+T_{j}}$ and we are done or $v_{i n}^{t+T_{J}}-$ $a_{i n}^{t+T_{j}^{*}}<0$. But if this inequality holds for all $j \in l(n)$, then $\Sigma_{j \in l(n)} v_{j n}^{t+T_{j}+1}=0$ and $\sum_{T=1}^{\tau}\left|\left[a_{i n}^{t+T}\right]^{-}\right| \geqslant\left|\left[v_{i n}^{t}\right]^{-}\right|$.

Q.E.D.

Proof OF Lemma 3: By Lemma 2 we have $p \cdot\left[\Sigma_{T=1}^{\tau}\left(x_{i}^{t+T}+y_{i}^{t+T}\right)\right]^{+} \geqslant \dot{p} \cdot\left[v_{i}^{t}\right]^{+}$. But $\Sigma_{i} p \cdot\left[x_{i}^{t+T}\right]^{+} \geqslant \Sigma_{i} p \cdot\left[y_{i}^{t+T}\right]^{+}$so $\Sigma_{i} p \cdot\left[\Sigma_{T=1}^{\tau} x_{i}^{t+T}\right]^{+} \geqslant \frac{1}{2} \Sigma_{i} p \cdot\left[v_{i}^{t}\right]^{+}$and $\left[v_{i}^{t+\tau}\right]^{+}=\left[v_{i}^{t}\right]^{+}-$ $\left[\Sigma_{T=1}^{\tau} x_{i}^{t+T}\right]^{+}$. Hence, $\Sigma_{i} p \cdot\left[v_{i}^{t+\tau}\right]^{+} \leqslant \frac{1}{2} \Sigma_{i} p \cdot\left[v_{i}^{t}\right]^{+}$.

Q.E.D.

ProOF OF THEOREM: By iteration of Lemma 3.

University of California, Davis

Manuscript received June, 1975.

\section{REFERENCES}

[1] Ostroy, Joseph M.: "The Informational Efficiency of Monetary Exchange," American Economic Review, 63 (1973), 597-610.

[2] Ostroy, Joseph M., AND Ross M. STARr: "Money and the Decentralization of Exchange," Econometrica, 42 (1974), 1093-1113. 